\title{
Effects of Quercetin on Human $\alpha$-Amino-3-hydroxy-5-methyl-4- isoxazolepropionic Acid Receptor-Mediated Ion Currents
}

\author{
Tae-Joon Shin, ${ }^{a, \#}$ Sun-Hye Chor,${ }^{a, \#}$ Byung-Hwan Lee, ${ }^{a}$ Mi Kyung Pyo, ${ }^{a}$ Sung-Hee Hwang, ${ }^{a}$ \\ Bo-Ra KIm, ${ }^{a}$ Sang-Mok LeE, ${ }^{a}$ Ye Sun Han,${ }^{b}$ Jun-Ho LeE, ${ }^{c}$ Ji-Ho PARK, ${ }^{d}$ Hyoung-Chun KIm, ${ }^{e}$ \\ Hyewhon RHIM, ${ }^{f}$ and Seung-Yeol NAH ${ }^{*, a}$ \\ ${ }^{a}$ Department of Physiology, College of Veterinary Medicine and Bio/Molecular Informatics Center, Konkuk University; \\ ${ }^{b}$ Advanced Technology Fusion, Konkuk University; Seoul 143-701, Korea: ' ${ }^{c}$ Department of Physiology, College of \\ Oriental Medicine, Kyung-Hee University; Seoul 130-701, Korea: ' ${ }^{d}$ Graduate School of East-West Medical Science, Kyung \\ Hee University; Kyunggi 449-701, South Korea: ${ }^{e}$ Neuropsychopharmacology and Toxicology Program, College of \\ Pharmacy, Kangwon National University; Chunchon 200-701, Korea: and ${ }^{f}$ Life Science Division, Korea Institute of \\ Science and Technology; Seoul 130-701, Korea. Received May 3, 2010; accepted June 21, 2010
}

\begin{abstract}
Quercetin is a low molecular weight flavonoid found in dietary fruits and vegetables. Quercetin, like other flavonoids, has demonstrated neuroprotective effects in vitro and in vivo. However, relatively little is known about how quercetin achieves its neuroprotective abilities. The $\alpha$-amino-3-hydroxy-5-methyl-4-isoxazolepropionic acid (AMPA) receptor is one of several excitatory receptors, which play an important role in postsynaptic neurotransmission. Over-stimulation of ionotropic glutamate receptor including AMPA receptors is closely associated with excitatory neurotoxicities. In the present study, we investigated the effects of quercetin on the glutamate-induced inward current $\left(I_{\mathrm{Glu}}\right)$ in Xenopus oocytes that heterologously express human AMPA receptor and stargazin, an auxiliary subunit of AMPA receptor. $I_{\text {Glu }}$ was measured using the two-electrode voltage clamp technique. In oocytes injected with cRNAs coding AMPA receptor (GluR1) and stargazin, quercetin inhibited $I_{\text {Glu }}$ in a reversible and concentration-dependent manner. The $\mathrm{IC}_{50}$ was 84.9 $\pm 15.0 \mu \mathrm{M}$. Quercetin action on $I_{\mathrm{Glu}}$ was attenuated by increasing glutamate concentration, and was membrane holding potential-dependent. These results show a possibility that quercetin interacts with AMPA receptor, which was heterologously expressed in Xenopus oocytes and that quercetin action on $I_{\mathrm{Glu}}$ of AMPA receptor could be one of contributions of quercetin-mediated neuroprotections.
\end{abstract}

Key words flavonoid; quercetin; $\alpha$-amino-3-hydroxy-5-methyl-4-isoxazolepropionic acid

Glutamate is one of the major excitatory neurotransmitters in the central nervous system. ${ }^{1)}$ Glutamate binds to various cation-gated glutamate receptors, which include $\alpha$-amino-3hydroxy-5-methyl-4-isoxazolepropionic acid (AMPA), $\mathrm{N}$ methyl-D-aspartate (NMDA) and kainate receptors. ${ }^{1,2)}$ Binding of glutamate to AMPA receptors mediates fast synaptic transmissions to induce postsynaptic depolarization and neuronal firing. ${ }^{3)}$ Thus, the activation of AMPA receptors are involved in various physiological functions of the nervous system such as learning and memory. In abnormal conditions, activation of AMPA receptors also induces excitotoxicity in the nervous system. ${ }^{4,5)}$ AMPA receptors consist of poreforming tetramer subunits GluR1-4, and each subunit can be alternatively spliced into either a flip or flop form. ${ }^{2,6}$ GluR1-4 are three homologous transmembrane proteins that bind extracellular glutamate, which forms the receptor's cation channel. On the other hand, mammalian AMPA receptors require TARP (transmembrane AMPA receptor regulatory proteins) auxiliary subunits. ${ }^{7)}$ The prototypical TARP, stargazin, is mutated in stargazer mice that suffer from absence epilepsy and cerebellar ataxia. ${ }^{8)}$ Stargazin is a four transmembrane protein and plays a important role in AMPA receptor trafficking and channel gating. 9,10$)$

Flavonoids are representative secondary metabolites and substances of low molecular weight found widely in fruits and vegetables. ${ }^{11)}$ They support various effects in the nervous system including analgesia, motility and sleep, anticonvulsant, sedative and anxiolytic effects. ${ }^{12-14)}$ A line of evidence supports that flavonoids including quercetin exhibit in vitro and in vivo neuroprotective effects. ${ }^{15,16)}$ Related with ligandgated ion channel regulations, recent reports have demonstrated that quercetin regulates the Cys-loop family of ligand-gated anion and cation channels such as $\gamma$-aminobutyric acid $A\left(\mathrm{GABA}_{\mathrm{A}}\right)$ and $\mathrm{GABA}_{\mathrm{C}}$, glycine, and $5-\mathrm{HT}_{3 \mathrm{~A}}$ receptors expressed in Xenopus laevis oocytes. ${ }^{17-20)}$ Although AMPA receptor is not a Cys-loop family receptor, it does play an important role in the nervous system physiologically or pathologically as one of the ligand-gated ion channels. ${ }^{1,2)}$ However, it is not clear whether AMPA receptor is involved in quercetin action and relatively little is known regarding how quercetin promotes its effect on AMPA receptor channel activity.

In this study, we investigated the effects of quercetin on the AMPA channel activity regulation expressed in Xenopus oocytes. For this study, we first expressed human AMPA receptor by co-injection of cRNAs of GluR1 and auxiliary subunit, stargazin in Xenopus oocytes and examined the effect of quercetin on glutamate-induced inward current $\left(I_{\mathrm{Glu}}\right)$. We used this system because: (1) Xenopus laevis oocytes have been widely used as a tool to express the membrane proteins encoded by exogenously administered cDNAs or cRNAs including receptors, ion channels, and transporters ${ }^{21)}$; and (2) AMPA receptor channels expressed in Xenopus oocytes by the co-injection of AMPA and stargazin cRNAs subunits are well studied and well characterised. ${ }^{10,22)}$ We found that co-application of quercetin with glutamate inhibited $I_{\mathrm{Glu}}$ with concentration-dependent and reversible manners. The inhibitory effects of quercetin on $I_{\mathrm{Glu}}$ were attenuated by high concen- 
trations of glutamate and were voltage-dependent. Thus, we demonstrated that quercetin is a novel agent that regulates AMPA receptor channel activity.

\section{MATERIALS AND METHODS}

Materials Human AMPA receptor and stargazin cDNAs were kindly provided by Dr. Susumu Tomita (Yale University School of Medicine, CT, U.S.A.). Quercetin (Fig. 1) and all other reagents were purchased from Sigma-Aldrich (St. Louis, MO, U.S.A.).

Preparation of Xenopus laevis Oocytes and Microinjection $X$. laevis frogs were purchased from Xenopus I (Ann Arbor, MI, U.S.A.). Animal care and handling were in accordance with the highest standards of Konkuk university guidelines. To isolate oocytes, frogs were anesthetised with an aerated solution of 3-amino benzoic acid ethyl ester, and the ovarian follicles were removed. The oocytes were separated with collagenase followed by agitation for $2 \mathrm{~h}$ in a $\mathrm{Ca}^{2+}$-free OR2 medium containing $82.5 \mathrm{~mm} \mathrm{NaCl}, 2 \mathrm{~mm} \mathrm{KCl}, 1 \mathrm{~mm}$ $\mathrm{MgCl}_{2}, 5 \mathrm{~mm} N$-(2-hydroxyethyl)piperazine- $N^{\prime}$-(2-ethanesulfonic acid) (HEPES), $2.5 \mathrm{~mm}$ sodium pyruvate, 100 units $/ \mathrm{ml}$ penicillin, and $100 \mu \mathrm{g} / \mathrm{ml}$ streptomycin. Stage V-VI oocytes were collected and stored in a ND96 medium $(96 \mathrm{~mm} \mathrm{NaCl}$, $2 \mathrm{mM} \mathrm{KCl}, 1 \mathrm{mM} \mathrm{MgCl}_{2}, 1.8 \mathrm{mM} \mathrm{CaCl}_{2}$, and $5 \mathrm{~mm}$ HEPES, $\mathrm{pH} 7.5$ ) supplemented with $50 \mu \mathrm{g} / \mathrm{ml}$ gentamicin. The solution containing the oocytes was maintained at $18^{\circ} \mathrm{C}$ with continuous gentle shaking and was replaced daily. Electrophysiological experiments were performed 3 to $5 \mathrm{~d}$ after oocyte isolation. For AMPA receptor experiments, AMPA receptor (GluR1)- and stargazin-encoding cRNAs (40 nl) were injected into the animal or vegetal pole of each oocyte $1 \mathrm{~d}$ after isolation using a $10-\mu 1$ microdispenser (VWR Scientific, West Chester, PA, U.S.A.) fitted with a tapered glass pipette tip $(15-20 \mu \mathrm{m}$ in diameter $){ }^{18)}$

Data Recording A custom-made Plexiglas net chamber was used for two-electrode voltage-clamp recordings, as previously reported. ${ }^{18)}$ A single oocyte was constantly superfused with a recording solution $(90 \mathrm{~mm} \mathrm{NaCl}, 1 \mathrm{~mm} \mathrm{KCl}$, $1.5 \mathrm{~mm} \mathrm{CaCl}_{2}$, and $10 \mathrm{~mm}$ HEPES, $\mathrm{pH}$ 7.4) in the absence or presence of glutamate or quercetin during recording. The microelectrodes were filled with $3 \mathrm{M} \mathrm{KCl}$ and had a resistance of $0.2-0.7 \mathrm{M} \Omega$. Two-electrode voltage-clamp recordings were obtained at room temperature using an Oocyte Clamp (OC-725C, Warner Instrument) and were digitised using Digidata 1200A (Molecular Devices, Sunnyvale, CA, U.S.A.). Stimulation and data acquisition were controlled using pClamp 8 software (Molecular Devices). For most electrophysiological data, the oocytes were clamped at a holding potential of $-70 \mathrm{mV}$. For current and voltage $(\mathrm{I}-\mathrm{V})$ relationship, voltage ramps were applied from -100 to $+50 \mathrm{mV}$ for $300-\mathrm{ms}$. In the different membrane-holding potential experiments, the oocytes were clamped at the indi-

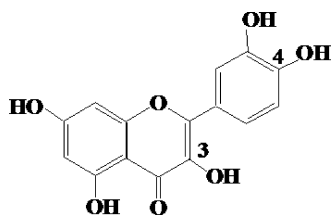

Fig. 1. Chemical Structure of Quercetin cated holding potentials. Linear leak and capacitance currents were corrected by means of the leak subtraction procedure.

Data Analysis To obtain the concentration-response curve for the effect of quercetin on the inward peak $I_{\mathrm{Glu}}$ mediated by the AMPA receptor, the $I_{\text {Glu }}$ peak was plotted at different concentrations of quercetin. Origin software (OriginLab Corp., Northampton, MA, U.S.A.) was used to fit the plot to the Hill equation: $I / I_{\max }=1 /\left[1+\left(\mathrm{IC}_{50} /[\mathrm{A}]\right)^{\mathrm{nH}}\right]$, where $I_{\max }$ was maximal current obtained from each $\mathrm{ED}_{50}$ value of glutamate in wild-type receptors, $\mathrm{IC}_{50}$ was the concentration of quercetin required to decrease the response by $50 \%$, [A] was the concentration of quercetin, and $\mathrm{nH}$ was the Hill coefficient. All values were presented as mean \pm S.E.M. The differences between the means of control and treatment data were determined using the unpaired Student's $t$-test. A value of $p<0.05$ was considered to be statistically significant.

\section{RESULTS AND DISCUSSION}

Effect of Quercetin on $I_{\text {Glu }}$ in Oocytes Expressing AMPA Receptor and the Auxiliary Subunit Stargazin In the present study, we examined the effect of quercetin on AMPA receptor channel activity. For this, we co-expressed AMPA receptor (GluR1) and the auxiliary subunit stargazin for the following reasons. The expression of AMPA receptor alone in Xenopus oocytes usually elicits small $I_{\mathrm{Glu}}$ and rapid desensitisation, ${ }^{9)}$ whereas co-expression of AMPA receptor with stargazin produces large $I_{\mathrm{Glu}}$ currents, reduces desensitisation and slows deactivation. ${ }^{9)}$ As shown in Fig. $2 \mathrm{~A}$, the addition of glutamate (Glu) to the bathing solution induced a large inward current $\left(I_{\mathrm{Glu}}\right)$ in oocytes injected with human AMPA receptor and stargazin cRNAs (Fig. 2). In $\mathrm{H}_{2} \mathrm{O}-\mathrm{in}-$ jected control oocytes, the application of glutamate did not induce any inward currents (data not shown). Quercetin itself also had no effect in oocytes expressing AMPA receptor and stargazin at a holding potential of $-70 \mathrm{mV}$ (data not shown). However, the co-application of quercetin $(200 \mu \mathrm{M})$ with glutamate $(10 \mu \mathrm{M})$ for $40 \mathrm{~s}$ inhibited $I_{\mathrm{Glu}}$ in oocytes expressing AMPA receptor (Fig. 2, $n=5-6$ from three different frogs). In concentration-dependent experiments with quercetin, coapplication with quercetin for $40 \mathrm{~s}$ decreased $I_{\mathrm{Glu}}$ in a concentration-dependent manner in oocytes expressing AMPA receptor (Fig. 2). Thus, co-application of quercetin decreased
A

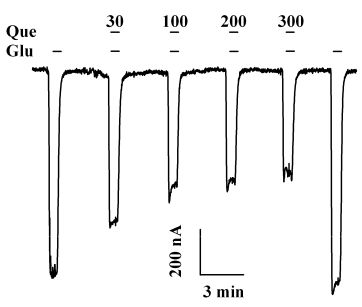

B

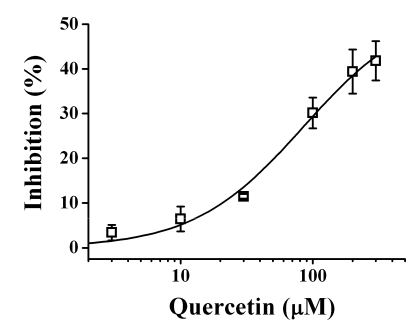

Fig. 2. Effect of Quercetin on $I_{\text {Glu }}$ in Oocytes Expressing AMPA Receptors

(A) Glutamate $(\mathrm{Glu} ; 10 \mu \mathrm{M})$ was applied first, followed by co-application of quercetin (Que) and Glu. Co-application of the indicated concentrations of quercetin with glutamate inhibited $I_{\mathrm{Gl}}$. Traces represent six separate oocytes from three different batches of frogs. (B) Concentration-dependent effects of quercetin co-application on $I_{\mathrm{Glu}}$. Quercetin inhibited $I_{\mathrm{Glu}}$ with concentration-dependent manner. 
A

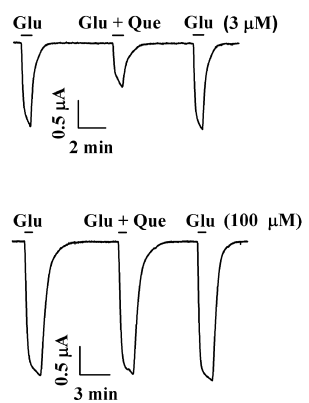

B

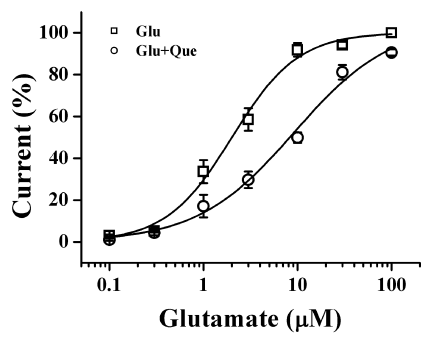

Fig. 3. Concentration-Dependent Effects of Glutamate on the Inhibitory Effects of Quercetin on $I_{\text {Glu }}$

(A) The representative Traces on the indicated concentrations of glutamate represent seven separate oocytes from three different batches of frogs. (B) Concentrationresponse relationships for glutamate in AMPA receptor treated with glutamate $(0.1-$ $100 \mu \mathrm{M})$ alone or with glutamate plus $200 \mu \mathrm{M}$ quercetin in oocytes expressing AMPA receptor. The normalized $I_{\text {Glu }}$ of oocytes expressing AMPA receptor was measured using the indicated concentration of glutamate in the absence $(\square)$ or presence $(\bigcirc)$ of $200 \mu \mathrm{m}$ quercetin (Que). Oocytes were exposed to glutamate alone or to glutamate with quercetin for $1 \mathrm{~min}$ before application. Oocytes were voltage-clamped at a holding potential of $-70 \mathrm{mV}$.

$I_{\text {Glu }}$ by $3.4 \pm 1.7,6.4 \pm 2.7,11.5 \pm 0.5,30.1 \pm 3.4,39.4 \pm 4.9$, and $41.8 \pm 4.4 \%$ at $3,10,30,100,200$, and $300 \mu \mathrm{m}$ in oocytes expressing AMPA receptors, respectively. The $\mathrm{IC}_{50}$ of $I_{\mathrm{Glu}}$ was $84.9 \pm 15.0 \mu \mathrm{M}$ for quercetin co-application with glutamate in oocytes expressing the AMPA receptor (Fig. 2B, $n=10-11$, with samples taken from three different frogs for each point).

Concentration-Dependent Effects of Glutamate in the Inhibitory Effect of Quercetin on $\boldsymbol{I}_{\text {Glu }}$ To further study the mechanism by which the co-application of quercetin inhibits $I_{\text {Gku }}$ in oocytes expressing AMPA receptor, we analysed the effect of quercetin on $I_{\mathrm{Glu}}$ evoked by different glutamate concentrations (Fig. 3). Co-application of quercetin for $40 \mathrm{~s}$ with different concentrations of glutamate significantly shifted the concentration-response curve of glutamate to the right $\left(\mathrm{EC}_{50}\right.$ values changed from $2.0 \pm 2.5$ to 9.2 $\pm 2.7 \mu \mathrm{M}, * p<0.05$ ), while the Hill coefficient was not significantly changed from $1.24 \pm 0.16$ to $0.84 \pm 0.12$, indicating that the number of quercetin molecule interacting with AMPA receptor was not changed. Thus, the inhibitory effects of quercetin on $I_{\mathrm{Glu}}$ were affected by increasing concentrations of glutamate in the range of 0.1 to $100 \mu \mathrm{M}$ glutamate (Fig. 3A), suggesting that quercetin inhibition on $I_{\text {Glu }}$ could be competitive to the glutamate binding site.

Current and Voltage Relationship in the Inhibitory Effect of Quercetin on $\boldsymbol{I}_{\text {Glu }}$ In experiments examining the current-voltage relationship, the membrane potential was held at $-70 \mathrm{mV}$, and a voltage ramp was applied from -100 to $+50 \mathrm{mV}$ for $300 \mathrm{~ms}$. In the absence of glutamate, the inward current at $-100 \mathrm{mV}$ was less than $0.2 \mu \mathrm{A}$, and the outward current at $+50 \mathrm{mV}$ was near $0.05 \mu \mathrm{A}$ (data not shown). The addition of glutamate to the bathing medium induced a mainly inward current at negative voltages and an outward current at positive voltages. ${ }^{23,24)} \mathrm{Co}$-application of quercetin with glutamate increased both inward currents. The reversal potential was near $-17 \mathrm{mV}$ for both glutamate alone and for glutamate with quercetin. ${ }^{23,24)}$ Also, the co-application of quercetin with glutamate further decreased currents but did not affect the AMPA receptor channel property because

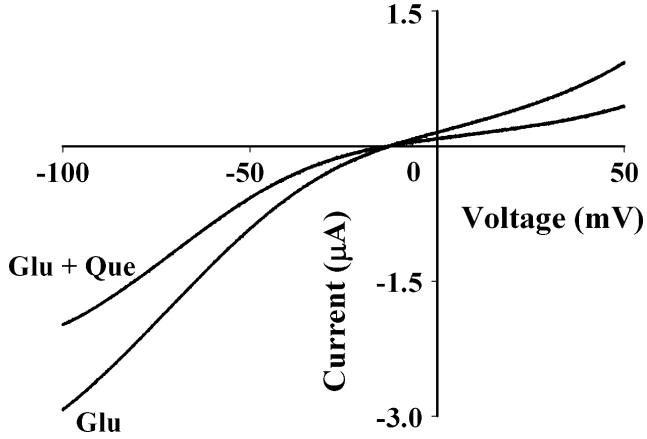

Fig. 4. Current-Voltage Relationships of $I_{\text {Glu }}$ Inhibition by Quercetin in AMPA Receptor

Representative current-voltage relationships were obtained using voltage ramps of -100 to $+50 \mathrm{mV}$ for $300 \mathrm{~ms}$ at a holding potential of $-80 \mathrm{mV}$. Voltage steps were applied before and after application of $10 \mu \mathrm{M}$ glutamate in the absence or presence of $200 \mu \mathrm{M}$ quercetin (Que). The reversal potential for the receptor was $-17.6 \pm 1.3 \mathrm{mV}$ and $-18.4 \pm 1.5 \mathrm{mV}$ in the absence or presence of quercetin, respectively.

\section{A}

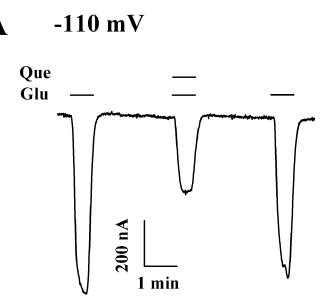

C $\quad-30 \mathrm{mV}$

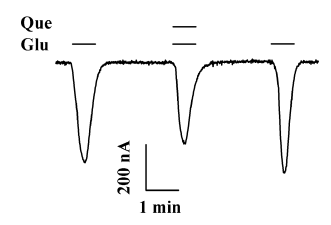

B

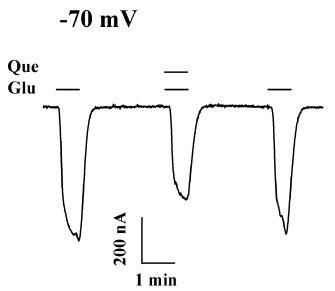

D

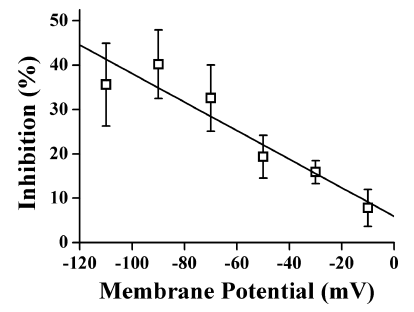

Fig. 5. Voltage-Dependent Inhibition of $I_{\text {Glu }}$ in AMPA Receptor by Quercetin

(A-C) The representative traces were obtained from the receptors in the absence or presence of quercetin (Que) at the indicated membrane holding potentials. (D) The summary of the percent inhibition induced by quercetin at the indicated membrane holding potentials in oocytes expressing the wild-type receptor. Each point represents the mean \pm S.E.M. ( $n=6-8 /$ group $)$.

quercetin did not change the reversal potential of AMPA receptor (Fig. 4). Interestingly, the inhibitory effect of quercetin on $I_{\mathrm{Glu}}$ was dependent on the membrane holding potential (Fig. 5). Quercetin decreased $I_{\text {Glu }}$ by $35.6 \pm 9.3$, $40.2 \pm 7.7,32.6 \pm 7.4,19.4 \pm 4.8,15.9 \pm 5.6$, and $7.8 \pm 4.2 \%$ at membrane holding potentials of $-110,-90,-70,-50$, -30 , and $-10 \mathrm{mV}$ in oocytes expressing AMPA receptor, respectively ( $n=5-7$, from three different frogs). However, we could observe that the reversal potential membrane was not changed in different membrane holding potentials (data not shown).

In vitro or in vivo over-stimulation of ionotropic glutamate receptors including AMPA receptor could be coupled to neurotoxicity. ${ }^{4,5,10,25-27)}$ Agents that regulate ionotropic glutamate receptor channel currents are studied for the development of neuroprotective agents through natural sources or synthesis. As a natural source, quercetin is one of several flavonoids and is a well-known anti-oxidant. ${ }^{11)}$ Recent studies 
have shown that the application of quercetin protects central nervous systems against oxidative effects and decreases learning and memory damage as well as ischemic brain damage. $^{28)}$ However, the beneficial roles of quercetin as one of the natural compounds in the nervous system are poorly understood, except for its anti-oxidant effects. Furthermore, little is known about the effects of quercetin on AMPA receptor channel activity, although AMPA receptor is widely expressed throughout the central nervous systems, including in the hippocampus.

We investigated the effects of quercetin on human AMPA receptor and stargazin heterologously expressed in Xenopus oocytes. We found that: (1) co-application of quercetin with glutamate induced an inhibition of $I_{\mathrm{Glu}}$ in a reversible and concentration-dependent manner; (2) $I_{\mathrm{Glu}}$ inhibition by quercetin co-application with glutamate was dependent on the concentration of glutamate. In other words, the high concentration of glutamate significantly attenuated quercetin action. Finally, (3) quercetin inhibition on $I_{\text {Glu }}$ was membrane holding potential-dependent, since quercetin action on $I_{\text {Glu }}$ was greatly decreased by more depolarising membrane potentials. These results revealed the possibility that quercetin interacts with AMPA receptor to exert its effect on $I_{\mathrm{Glu}}$.

In previous reports we discovered that the application of quercetin inhibits 5-HT- and glycine-induced peak inward currents $\left(I_{5-\mathrm{HT}}\right.$ and $\left.I_{\mathrm{Gly}}\right)$ of mouse $5-\mathrm{HT}_{3 \mathrm{~A}}$ and human glycine a receptor channels expressed in Xenopus laevis oocytes. Inhibition of $I_{5-\mathrm{HT}}$ by quercetin was both competitive and voltage-independent, whereas inhibition of $I_{\text {Gly }}$ by quercetin was non-competitive and voltage-dependent. ${ }^{18,19)}$ In the current study, we also investigated how quercetin regulates AMPA receptor channel activities by measuring the effect of quercetin on different concentrations of glutamate for AMPA receptors. Interestingly, the $\mathrm{IC}_{50}$ value on AMPA receptor channel activity regulation was a little higher than those of Cys-loop family of ligand-gated ion channels examined above but was lower than those of $\mathrm{K}^{+}$channel. ${ }^{29,30)}$ Thus, the different $\mathrm{IC}_{50}$ values of quercetin might be derived from different quercetin affinity between ion channels and receptors.

In the presence of quercetin, a significant rightward shift in the glutamate concentration-response curve was obtained, and current inhibition was relieved at high glutamate concentrations. Thus, the inhibitory effect of quercetin on $I_{\mathrm{Glu}}$ in AMPA receptors was almost abolished at $100 \mu \mathrm{M}$ glutamate. These results show that a competition of quercetin with glutamate might be involved in quercetin regulation of AMPA receptor channel activity regulation. Moreover, we found that quercetin inhibited $I_{\text {Glu }}$ via a membrane holding potentialdependent manner in oocytes expressing AMPA receptor. In other words, quercetin action on $I_{\mathrm{Glu}}$ was greatly attenuated at more depolarizing potentials (Fig. 5). These results show a possibility in nervous systems that although quercetin could exerts its inhibitory effects on $I_{\mathrm{Glu}}$ after AMPA receptor activation at near resting membrane, quercetin action on $I_{\mathrm{Glu}}$ might be decreased or lost after further depolarization. In addition, these results also raise a possibility that quercetin may act as an open channel blocker of AMPA receptor, despite lacking a charged group. Open channel blockers such as local anesthetics or hexamethonium are strongly voltage-dependent due to the charge that they carry in the transmembrane electrical field. ${ }^{31-33)}$ Similarly, in our previous report, ginsenoside $\mathrm{Rg}_{3}$, an active ingredient of Panax ginseng, inhibits acetylcholine-mediated ion currents with membrane potential-dependent manner in oocytes expressing mutant L247T $\alpha 7$ nicotinic acetylcholine receptor channel currents. ${ }^{34)}$ We also demonstrated that ginsenoside $\mathrm{Rg}_{3}$ inhibits inward cation currents through the open state of the V291A $5-\mathrm{HT}_{3 \mathrm{~A}}$ receptor, which exhibits constitutively active ion currents. ${ }^{35)}$ These results suggest that quercetin acts as a noncharged open channel blocker of cation ligand-gated ion channels. Taken together, although quercetin regulates AMPA receptor channel activity with glutamate-concentration dependent and membrane holding potential dependent manners, further studies might be required for elucidation of the detailed mechanism of quercetin action on AMPA receptor channel activity.

It might be questionable whether flavonoids containing quercetin inhibiting $I_{\mathrm{Glu}}$ influence on action potential of neuron. Until now there is no direct evidence that flavonoids including quercetin affect on action potential of neurons. However, previous reports show the possibility that flavonoids including quercetin might negatively influence on neuronal excitability, since flavonoids including quercetin inhibit ion channels closely related with action potential induction. For example, Jia et al. ${ }^{36)}$ and Yao et al. ${ }^{37)}$ showed that quercetin and genistein inhibited voltage-dependent $\mathrm{Na}^{+}$channes in hippocampal and superior cervical ganglion neurons, respectively. In addition, Wu et l $^{38)}$ showed that quercetin also inhibited voltage-dependent $\mathrm{Ca}^{2+}$ channel in neuronal NG10815 cells

The activation of AMPA receptor in the nervous system is closely related with neurotoxicity, neurodegenerative disease, and ischemia. ${ }^{4,55-27)}$ Quercetin attenuates in vitro and in vivo excitotoxin-mediated insults. ${ }^{15,16,39,40)}$ The present findings on the inhibitory effects of quercetin on AMPA receptor channel activity with voltage-dependent manner might be one of the main contributors to neuroprotection against AMPA receptor-related neurotoxicity. ${ }^{24)}$ However, it appears that the measured concentrations of flavonoids including qurecetin in rat brain and plasma after oral administration of standardized Gingko bilboa (EGb 761), which is rich in flavonoids, was in the range of nM. ${ }^{41)}$ The concentration is much less than those of flavonoids including quercetin exhibiting various in vitro neuropharmacological actions including the present study. ${ }^{15,16)}$ Therefore, we must be careful to explain the beneficial effects of flavonoids including quercetin in nervous systems.

In conclusion, we found that the flavonoid quercetin inhibited $I_{\mathrm{Glu}}$ in a glutamate concentration- and membrane holding potential-dependent manner in Xenopus oocytes expressing AMPA receptor. Our results indicate that quercetin is a novel agent interacting with AMPA receptor and that the inhibitory effects of quercetin on $I_{\mathrm{Glu}}$ of AMPA receptor could provide a molecular basis for the pharmacological actions of flavonoids in the nervous systems.

Acknowledgements This work was supported by Basic Science Research Program through the National Research Foundation of Korea (NRF) funded by the Ministry of Education, Science and Technology (R01-2008-000-10448-0), Priority Research Centers Program through the National Research Foundation of Korea (NRF) funded by the Ministry of 
Education, Science and Technology (2009-0093824), and BK21 to S. Y. Nah.

\section{REFERENCES}

1) Keinänen K., Wisden W., Sommer B., Werner P., Herb A., Verdoorn T. A., Sakmann B., Seeburg P. H., Science, 249, 556-660 (1990).

2) Hollmann M., Heinemann S., Annu. Rev. Neurosci., 17, 31-108 (1994).

3) Jonas P., Sakmann B., J. Physiol. (London), 455, 143-171 (1992).

4) Kwak S., Weiss J. H., Curr. Opin. Neurobiol., 16, $281-287$ (2006).

5) Soundarapandian M. M., Tu W. H., Peng P. L., Zervos A. S., Lu Y., Mol. Neurobiol., 32, 145-155 (2005).

6) Seeburg P. H., Trends Neurosci., 16, 359-365 (1993).

7) Nicoll R. A., Tomita S., Bredt D. S., Science, 311, 1253-1256 (2006)

8) Letts V. A., Felix R., Biddlecome G. H., Arikkath J., Mahaffey C. L., Valenzuela A., Bartlett F. S., Mori Y., Campbell K. P., Frankel W. N., Nat. Genet., 19, 340-347 (1998).

9) Tomita S., Sekiguchi M., Wada K., Nicoll R. A., Bredt D. S., Proc. Natl. Acad. Sci. U.S.A., 103, $10064-10067$ (2006).

10) Tomita S., Shenoy A., Fukata Y., Nicoll R. A., Bredt D. S., Neuropharmacology, 52, 87-91 (2007).

11) Harborne J. B., Williams C. A., Phytochemistry, 55, 481-504 (2000).

12) Speroni E., Minghetti A., Planta Med., 54, 488-491 (1998).

13) Medina J. H., Viola H., Wolfman C., Marder M., Wasowski C., Calvo D. J., Paladini A. C., Phytomedicine, 5, 235-243 (1998).

14) Viola H., Wasowski, C., Levi de Stein M., Wolfman C., Silveira R., Dajas F., Medina J. H., Paladini A. C., Planta Med., 61, 11-14 (1995).

15) Schültke E., Kamencic H., Zhao M., Tian G. F., Baker A. J., Griebel R. W., Juurlink B. H., J. Neurotrauma, 22, 1475-1484 (2005).

16) Silva B., Oliveira P. J., Dias A., Malva J. O., Neurotox. Res., 13, 265 279 (2008)

17) Goutman J. D., Waxemberg M. D., Doñate-Oliver F., Pomata P. E., Calvo D. J., Eur. J. Pharmacol., 461, 79-87 (2003).

18) Lee B. H., Jeong S. M., Lee J. H., Kim J. H., Yoon I. S., Lee J. H., Choi S. H., Lee S. M., Chang C. G., Kim H. C., Han Y., Paik H. D., Kim Y., Nah S. Y., Mol. Cells, 20, 69-73 (2005).

19) Lee B. H., Lee J. H., Yoon I. S., Lee J. H., Choi S. H., Pyo M. K., Jeong S. M., Choi W. S., Shin T. J., Lee S. M., Rhim H., Park Y. S., Han Y. S., Paik H. D., Cho S. G., Kim C. H., Lim Y. H., Nah S. Y., Brain Res., 1161, 1-10 (2007).

20) Lee B. H., Pyo M. K., Lee J. H., Choi S. H., Shin T. J., Lee S. M., Lim Y., Han Y. S., Paik H. D., Cho S. G., Yun-Choi H. S., Rhim H., Nah S. Y., Biol. Pharm. Bull., 31, 611-617 (2008).

21) Dascal N., CRC Crit. Rev. Biochem., 22, 317-387 (1987).
22) Schmidt C., Klein C., Hollmann M., J. Mol. Biol., 390, 182-195 (2009).

23) Boulter J., Hollmann M., O'Shea-Greenfield A., Hartley M., Deneris E., Maron C., Heinemann S., Science, 249, 1033-1037 (1990).

24) Akinshola B. E., Taylor R. E., Ogunseitan A. B., Onaivi E. S., Naunyn Schmiedebergs Arch. Pharmacol., 360, 242-248 (1990).

25) Tomita S., Byrd R. K., Rouach N., Bellone C., Venegas A., O’Brien J. L., Kim K. S., Olsen O., Nicoll R. A., Bredt D. S., Proc. Natl. Acad. Sci. U.S.A., 104, 18784-18788 (2007).

26) Mizuno T., Zhang G., Takeuchi H., Kawanokuchi J., Wang J., Sonobe Y., Jin S., Takada N., Komatsu Y., Suzumura A., FASEB J., 22, 1797 1806 (2008).

27) Kiagiadaki F., Savvaki M., Thermos K., Neuropharmacology, 58, 297-303 (2010).

28) Yao Y., Han, D. D., Zhang T., Yang Z., Phytother. Res., 24, 136-140 (2010).

29) Scholz E. P., Zitron E., Kiesekcer C., Luck S., Thomas D., Kathofer S., Kreye V. A. W., Katus H. A., Kiehn J., Schoels W., Karle C. A., Naunyn-Schiedeberg's Arch. Pharmacol., 371, 516-525 (2005).

30) Scholz E. P., Zitron E., Kiesekcer C., Luck S., Thomas D., Kathofer S., Kreuzer C., Bauer A., Katus H. A., Remppis A., Karle C. A., Greten J., Nutrition, Metabolism \& Cardiovascular Diseases, 17, 666-675 (2007).

31) Sine S. M., Taylor P., J. Biol. Chem., 257, 8106-8114 (1982).

32) Heidmann T., Oswald R. E., Changeux J. P., Biochemistry, 22, 3112 3127 (1983).

33) Arias H. R., Mol. Membr. Biol., 73, 1-17 (1996).

34) Lee B. H., Choi S. H., Pyo M. K., Shin T. J., Hwang S. H., Kim B. R., Lee S. M., Lee J. H., Lee J. H., Lee H. S., Choe H., Han K. H., Kim H. C., Rhim H., Yong J. H., Nah S. Y., Mol. Cells, 27, 591-599 (2009).

35) Lee B. H., Lee J. H., Lee S. M., Jeong S. M., Yoon I. S., Lee J. H., Choi S. H., Pyo M. K., Rhim H., Kim H. C., Jang C. G., Lee B. C., Park C. S., Nah S. Y., Neuropharmacology, 52, 1139-1150 (2007).

36) Jia Z., Jia Y., Liu B., Zhao Z., Jia Q., Liang H., Zhang H., Pflugers Arch., 456, 857-866 (2008).

37) Yao Y., Han D. D., Zhang T., Yang Z., Phytother. Res., 24, 136-140 (2010).

38) Wu S. N., Chiang H. T., Shen A. Y., Lo Y. K., J. Cell. Physiol., 195, 298-308 (2003).

39) Dajas F., Rivera F., Blasina F., Arredondo F., Echeverry C., Lafon L., Morquio A., Heizen H., Neurotox. Res., 5, 425-432 (2003).

40) Zhu J. T., Choi R. C., Chu G. K., Cheung A. W., Gao Q. T., Li J., Jiang Z.Y., Dong T. T., Tsim K. W., J. Agric. Food Chem., 55, 2438-2445 (2007).

41) Rangel-Ordóñez L., Nöldner M., Schubert-Zsilavecz M., Wurglics M., Planta Med. (2010) (in press). 